\title{
Endoglin Upregulation in the Liver after Bile Duct Ligation in Rats
}

\author{
Fernando Pérez-Barriocanal ${ }^{1}$, Neil G. Docherty ${ }^{1}$, Miguel Arévalo ${ }^{2}$, Annette Düwel ${ }^{1}$, \\ Juan V. Rivas-Elena ${ }^{1}$, José M. González-Buitrago ${ }^{3}$, Alejandro Esteller ${ }^{1}$, \\ Carmelo Bernabeu ${ }^{4}$ and José M. López-Novoa ${ }^{1, *}$ \\ ${ }^{I}$ Instituto Reina Sofía de Investigación Nefrológica, Departamento de Fisiología y Farmacología, Spain \\ ${ }^{2}$ Departamento de Anatomía e Histología Humanas, Universidad de Salamanca, Salamanca, España \\ ${ }^{3}$ Departamento de Bioquímica y Biología Molecular, Universidad de Salamanca, Salamanca, España \\ ${ }^{4}$ Centro de Investigaciones Biológicas, CSIC, Madrid, España
}

\begin{abstract}
Background: Transforming growth factor beta 1 (TGF- $\beta 1$ ) has been implicated in the stimulation of extracellular matrix synthesis in acute and chronic liver disease. Endoglin (CD-105) is a membrane glycoprotein that binds TGF- $\beta 1$ with high affinity. Endoglin is overexpressed in several model of fibrosis. The goal of the present study was to evaluate the effect of bile duct ligation (BDL) on endoglin expression and the effect of endoglin overexpression on liver fibrosis in rats.

Methods: Rat livers were transfected with a vector containing full length human endoglin (h-end) or an empty vector (mock) and 48 hours after were subjected to either BDL or sham operation (SO). Eighteen days after, a blood sample was obtained and bilirubin and serum enzyme activities were measured to assess liver damage. Liver fibrosis was quantified by a computer-assisted image analysis of Sirius red stained livers and by liver hydroxyproline content. Endoglin expression in the liver tissue was assessed by Western blot and immunohystochemistry.

Results: Both immunohistochemistry and Western blot reveals endoglin upregulation after BDL in rats. In addition, these techniques also reveal effective human endoglin transfection in the rat's liver. After BDL, liver fibrosis and plasma levels of enzymes were similar in h-end transfected and mock-transfected rats. Western blots showed higher endoglin expression after BDL in h-end transfected and mock-transfected rats.
\end{abstract}

Conclusions: The present study provides clear evidence that endoglin is upregulated in the liver of rats with BDL. h-end overexpression did not improve liver fibrosis after BDL in rats.

Keywords: Bile-duct ligation, endoglin, liver cirrhosis, liver fibrosis, transfection, transforming growth factor-beta.

\section{BACKGROUND}

Transforming growth factor- $\beta$ (TGF- $\beta$ ), a regulator of cell growth and differentiation, plays a central role in the response to injury. Active TGF- $\beta$ binds to specific, highaffinity receptors present on most cells, initiating a signalling cascade that results in many biological effects, including production of cytokines and inflammatory mediators, stimulation of extracellular matrix (ECM) synthesis and inhibition of ECM degradation [1-5]. Two signalling receptors, termed type I and type II, mediate the biologic actions of TGF- $\beta$. The extracellular domain of the type II receptor [6] binds the ligand, causing formation of heteromeric complexes incorporating type I and type II receptors [7]. The type II receptor then transphosphorylates the type I receptor, activating its kinase and initiating downstream signalling [7]. Thus, the type II receptor appears to be essential for the biological

*Address correspondence to this author at the Department of Physiology and Pharmacology, University of Salamanca, Salamanca, Spain;

Tel: +34 923294669; Fax: +34 923294472;

E-mails: jmlnovoa@usal.es,jmlnovoa@telefonica.net activity of TGF- $\beta$ in vivo [7-10]. In several organs, repeated or prolonged injury leads to progressive fibrosis and, ultimately, to the development of excessive, unwanted scarring. The late stage of this process in the liver is termed cirrhosis. TGF- $\beta$ appears to have a major regulatory role in this process, as shown both in animal models [11-14] and human hepatic injury [15-17]. Similarly, transgenic mice overexpressing TGF- $\beta 1$ and adenovirus-mediated gene transfer of TGF- $\beta$ are characterized by fibrosis in many organs including the liver [18, 19].

Endoglin, also known as CD105, is a 180 -kD homodimeric membrane glycoprotein expressed by human endothelial cells [20, 21], macrophages [22], vascular smooth muscle cells [23], mesangial cells [24] and fibroblasts [21]. Endoglin binds TGF- $\beta 1$ and TGF- $\beta 3$ with high affinity in human endothelial cells [25], in association with the type II receptor [26]. We have reported that endoglin is upregulated in several models of renal fibrosis in rats and mice [27, 28]. Endoglin has been also shown to be upregulated in other fibrotic tissues [29, 30]. 
Bile duct ligation (BDL) is an experimental manoeuvre that leads to liver fibrosis, a process likely to be mediated by TGF- $\beta 1$ overexpression $[31,32]$. The goal of the present study was to evaluate the effect of BDL and the subsequent liver fibrosis on endoglin expression in rats. As we have previously shown that endoglin is able to counteract the profibrotic effects of TGF- $\beta 1$ [24], we have assessed if endoglin overexpression had a beneficial effect on liver fibrosis after BDL.

\section{METHODS}

\section{Animals}

Male Wistar rats weighing initially around $250 \mathrm{~g}$ born and raised in the animal facilities of the Universidad de Salamanca were used in the present study. Rats were housed in standard cages in a room controlled for daylight $(12 \mathrm{~h})$, temperature $\left(20^{\circ} \mathrm{C}\right)$ and humidity $(60 \%)$ and maintained on a standard rat pellet diet. All experimental protocols were performed according to the guidelines for the ethical treatment of the animals, as specified by the European Union (86/609 and 98/81) and the Ministerio de Agricultura, Pesca y Alimentación de España.

\section{Experimental Groups}

The animals were distributed in four experimental groups. MOCK-SO: sham operated rats and transfected with transfection vehicle $(n=7)$. MOCK-BDL: rats with bile duct ligation and transfected with vehicle solution $(n=12)$. ENDSO: rats subjected to a sham operation then transfected with endoglin $(n=7)$. END-BDL: rats with bile duct ligation and transfected with endoglin $(n=10)$.

\section{Liver Endoglin Gene Delivery}

The pCMV plasmid, derived from the pCMV5 vector, and containing the human pCMV promoter, a universal intron, and downstream polyadenylation signals, has been previously described [33]. The pCMV-EndoL vector, containing the human L-endoglin isoform driven by the cytomegalovirus promoter, was constructed by inserting the $2.3-\mathrm{kb} E c o \mathrm{RI}$ endoglin cDNA, obtained by digestion of pcEXV-EndoL, into the EcoRI digested pCMV vector (Invitrogen) as previously described [34]. Liver transfection with the pCMVEndoL vector (h-end transfection) containing the human Lendoglin or the pCMV plasmid without endoglin (Mocktransfection) was performed as previously described [35]. In brief, rats were anaesthetised with 2-2-2 tribromoethanol and a small left subcostal incision was performed, the spleen was exposed and punctured with a PE-50 catheter [36]. $20 \mu \mathrm{g}$ of plasmid (at a ratio of $1 \mu \mathrm{g}$ of DNA/ $\mu$ l of TransIT polymer) in a final volume of $1 \mathrm{ml}$ was slowly infused during 3-5 min.

\section{Bile Duct Ligation}

After 48 hours, rats were anaesthetised with 2-2-2tribromoethanol and, under aseptic techniques, subjected to either bile duct ligation (BDL) and excision or sham operation (SO), as previously described [37].

Eighteen days later rats were anaesthetized with 2-2-2tribromoethanol. After opening the abdomen via a midline incision, the abdominal aorta was punctured and $5 \mathrm{ml}$ of blood obtained in heparinized tubes. Plasma and cells were separated by centrifugation in refrigerated conditions. Perfusion with saline was then performed through the abdominal aorta to remove blood from the body. A section of liver tissue was trimmed down and used for histochemical studies, hydroxyproline determinations and Western blot studies.

\section{Biochemical Analysis}

The activities of alanine aminotransferase, aspartate aminotransferase, alkaline phosphatase (EC 3.1.3.1.) and the concentration of total bilirrubin in plasma were determined by standard auto-analyser methods on a CIBA CORNING 550 Express. Liver hydroxyproline determinations were performed as previously described by us [38].

\section{Histological Studies}

A piece of the liver was trimmed down and fixed by immersion in $4 \%$ buffered formalin for 24 hours. After dehydration, pieces were embedded in paraffin. Sections $3 \mu \mathrm{m}$ thick were cut, mounted on glass slides and processed either for Masson's Trichrome or immunohistochemistry for light microscopy analyses.

Immunohistochemistry was performed on buffered formalin fixed, paraffin-embedded tissues. Briefly, $3 \mu \mathrm{m}$ sections were deparaffined in xylene and rehydrated in graded ethanol before staining with the peroxidase-anti peroxidase method. Endogenous peroxidase was blocked by incubation in $3 \%$ hydrogen peroxide.

For the detection of endoglin, a monoclonal mouse antihuman CD105, clone SN6h (1:400 dilution, 1 hour; DAKO CA, USA) was used. Following washes in PBS, the sections were sequentially incubated with the DAKO LSAB+HRP 2 system and finally 3,3'-diaminobenzidine (DAB) was used as chromogen.

For TGF- $\beta 1$ a polyclonal rabbit anti-human antiserum (1:50 dilution, 1 hour; Sta. Cruz Biotechnology, Ca, USA) was used. The sections were then rinsed in PBS and the avidin-biotin-complex immunoperoxidase method (rabbit ABC Staining System, Santa Cruz Biotechnology, CA, USA) that uses 3,3'-diaminobenzidine as a substrate were used.

Slides from both techniques were counterstained with hematoxylin, washed in water, dehydrated and mounted with a coverslip using Tissue-Tek (Miles Inc. IN, USA). Negative controls were prepared without primary antibody.

Morphometric studies were performed on $5 \mu \mathrm{m}$ sections by means of a computer-based image analysis system. In brief, sections were stained with Sirius red. Images were captured by a high-resolution videocamera (SONY ccd-iris) connected to a light microscope (Leitz Laborlux S) trough a green optical filter (IF 550), using the 20x objective. The evaluation and image analysis procedures were performed with specific software developed on the Visilog 4.1 image analyses program (Fibrosis HR. Master Diagnostica. Granada. Spain) whose application to assess liver fibrosis has been previously described by us [38]. A total of 15 images of each liver slide were captured and processed. For bile ductligated groups, two sets of images were captured and analyzed separately: one of periportal and septal areas and another of parenchymal areas. For each image, the values of 
fibrosis area were obtained in $\mu \mathrm{m}^{2}$ from the morphometric analysis. These values, saved in data ASCII files conveniently labeled, can be exported to any statistical analysis program and calculate several parameters that can express the degree of liver fibrosis in an objective and quantitative way.

Because hepatic fibrosis is a focal phenomenon and because it is possible to observe fields with markedly different degrees of lesion, the results of the image analysis study were expressed as frequency distribution diagrams in order to give more information on data dispersion.

\section{Western Blot}

Hepatic cell membranes were obtained by differential centrifugation of homogenized powdered tissue. The protein content was determined by a commercially available variant of the Lowry method (Bio-Rad) using BSA as standard. Protein samples were separated by $10 \%$ SDS-polyacrylamide gel electrophoresis and transferred to PVDF membrane (Pall-Gelman). Membranes were blocked with blocking buffer and incubated for 90 minutes with three different mouse anti-human endoglin monoclonal anti-bodies: P3D1, that reacts with the $\mathrm{N}$-terminal region of 204 amino acids encoded by exons 1 to 5 [39]. P4A4 that binds to a region of 54 amino acids encoded mostly by exon 7 [39] and TEA1/62.2 [40]. Membranes were washed, incubated for 30 minutes in standard buffer containing horseradish peroxidase-labeled goat anti-mouse IgG (Bio-Rad Laboratories) diluted 1:20000 and washed extensively. The presence of human endoglin dimers, with a characteristic band of 180 $\mathrm{kDa}$, was detected using a chemiluminescence assay (ECL detection reagents, Amersham) and recorded on an x-ray film. As a load control we have used tubulin and $\alpha$-actin. However, both proteins increased after BDL. Thus, we have chosen to carefully load the same amount of proteins per lane. Intensity of the bands in the film were quantified by densitometry using Scion Image software (Scion Corporation, Frederick, Maryland USA).

\section{Statistical Analysis}

One-way analysis of variance was performed using the NCSS program (V 6.0.10). Values from data with a normal distribution were expressed as mean $\pm \mathrm{EEM}$ with the Scheffe's correction test employed for multiple comparison. For data not conforming to a normal distribution, values were expressed as median and the Kruskal-Wallis $Z$ value test was used for multiple comparison. $\mathrm{P}<0.05$ or $\mathrm{Z}>1.96$ were considered statistically significant.

\section{RESULTS}

Data on body weight, liver weight and survival is shown in Table 1. Body weight increase was higher in non-ligated $($ MOCK-SO $=91 \mathrm{~g}$; END-SO $=95 \mathrm{~g}$ ) than in bile duct ligated rats $($ MOCK-BDL $=71 \mathrm{~g}$; END-BDL $=61 \mathrm{~g}$ ). Liver weight and hepatosomatic ratio was higher in ligated than in non-ligated rats. BDL rats had a lower survival than shamoperated rats.

\section{Effect of BDL on Endoglin Expression}

No endoglin expression in the liver was detectable in MOCK-SO animals by immunohistochemistry using the SN6h anti-human endoglin antibody (Fig. 1A). After BDL (MOCK-BDL rats), endoglin is clearly expressed in nonparenchymal cells. In addition, a clear expression was also observed in fibrosed areas around areas of ductular proliferation (Fig. 1C).

Fig. (2A) shows a representative western blot performed in liver extracts from MOCK-SO and MOCK-BDL rats, and revealed with the $\mathrm{P} 4 \mathrm{~A} 4$ anti-endoglin antibody, that recognize both human and rat endoglin. Fig. (2B) shows the quantification (in arbitrary units, and corrected by tubulin content of 8 samples per group) in two different blots. We can observe that MOCK-BDL rats had higher endoglin liver content than MOCK-transfected rats. Similar results were obtained by using other two different anti-endoglin antibodies, P3D1 and TEA (data not shown).

\section{Efficiency of Endoglin Transfection}

While in MOCK-SO rats endoglin expression by immunohistochemistry was almost undetectable by immunohistochemistry using the SN6h anti-human endoglin antibody (Fig. 1A and insert), rats transfected with human endoglin (END-SO) showed a diffuse expression of endoglin in the liver, mainly in sinusoid endothelial cells (Fig. 1B and insert). The endoglin expression in END-BDL animals (Fig. 1D) was higher than the expression in MOCK-BDL rats (Fig. 1C). In both groups, endoglin expression was strongly detected in sinusoid endothelial cells and in conserved and altered hepatocyte plates.

Western blots studies using the P4A4 antibody also reveals that endoglin expression was higher in END-SO than in MOCK-SO group (Fig. 3). Furthermore, endoglin content was higher in the END-BDL than in MOCK-BDL group (Fig. 3). Similar results were obtained by using other two different anti-endoglin antibodies, P3D1 and TEA (data not shown).

Table 1. Evolution of Body Weight (BL: before Bile Duct Ligation; AL: after Bile Duct Ligation), Liver Weight and Hepatosomatic Ratio (H.R.) at the end of the Experiment and Survival in Bile Duct Ligated and non Ligated Rats

\begin{tabular}{|c|c|c|c|c|c|}
\hline & \multicolumn{2}{|c|}{ Body Weight } & Liver Weight & H. R. \\
\hline & BL & AL & & $0,038 \pm 0,001$ \\
\hline \hline MOCK-SO & $241 \pm 10$ & $332 \pm 12^{\mathrm{a}}$ & $12.7 \pm 0.7$ & $100 \%$ \\
\hline MOCK-BDL & $250 \pm 8$ & $321 \pm 8^{\mathrm{a}}$ & $17.4 \pm 1.1^{\mathrm{b}}$ & $0,054 \pm 0,004^{\mathrm{b}}$ & $59 \%$ \\
\hline END-SO & $234 \pm 2$ & $329 \pm 6^{\mathrm{a}}$ & $12.4 \pm 0.4$ & $0,037 \pm 0,001$ & $100 \%$ \\
\hline END-BDL & $238 \pm 11$ & $299 \pm 20^{\mathrm{a}}$ & $17.5 \pm 1.2^{\mathrm{b}}$ & $0,058 \pm 0,008^{\mathrm{b}}$ & $50 \%$ \\
\hline
\end{tabular}

Values are means \pm EEM. Statistical significance: ${ }^{a}: \mathrm{p}<0.05$ vs BL; ${ }^{b}: \mathrm{p}<0.05$ vs SO. 


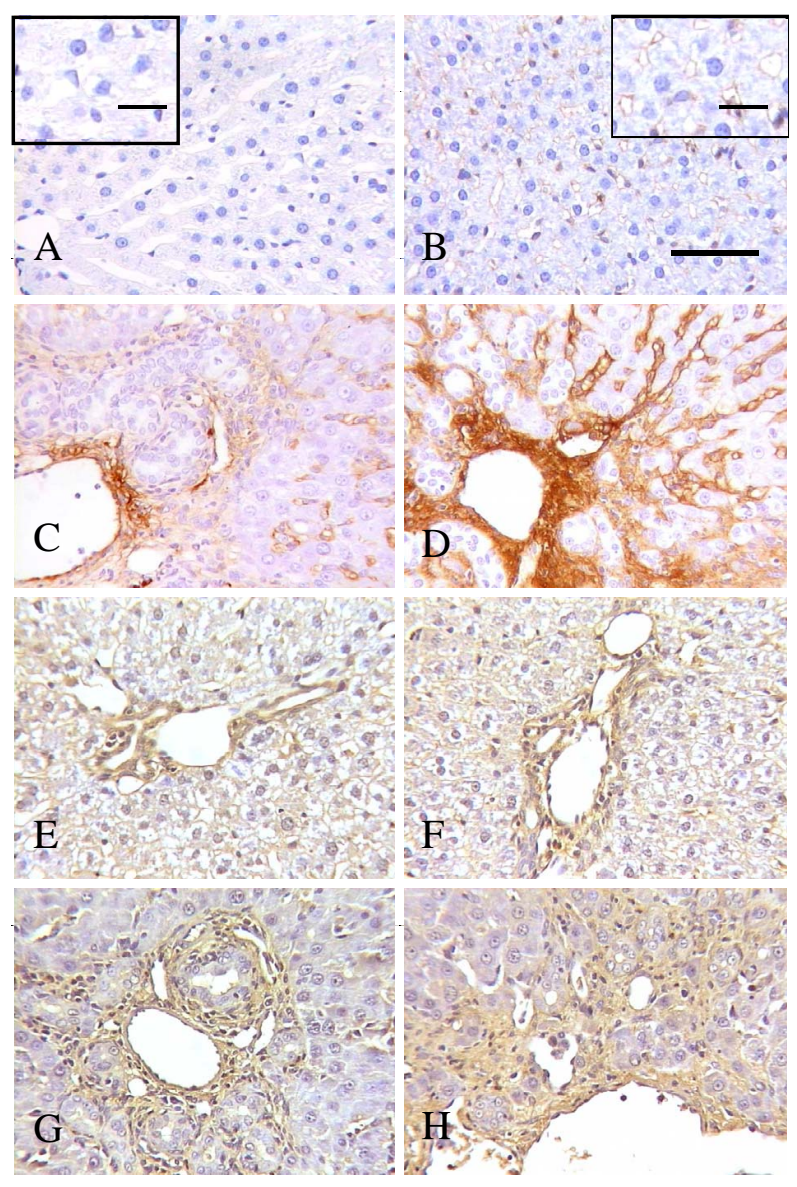

Fig. (1). Light micrographs of endọ lin (A to D) and TGF- $\beta 1$ (E t, $\mathbf{H})$ immunostaining of liver cortex corresponding to MOCK-SO: sham operated rats and transfected with vehicle solution (A and $\mathbf{E}$ ). MOCK-BDL: rats with bile duct ligation and transfected with vehicle solution $(\mathbf{C}$ and $\mathbf{G})$. END-SO: rats subjected to a sham operation then transfected with endoglin (B and $\mathbf{F})$. END-BDL: rats with bile duct ligation and transfected with endoglin (D and $\mathbf{H})$. Bar is $50 \mu \mathrm{m}$. in the figures and $20 \mu \mathrm{m}$. in the inserts.

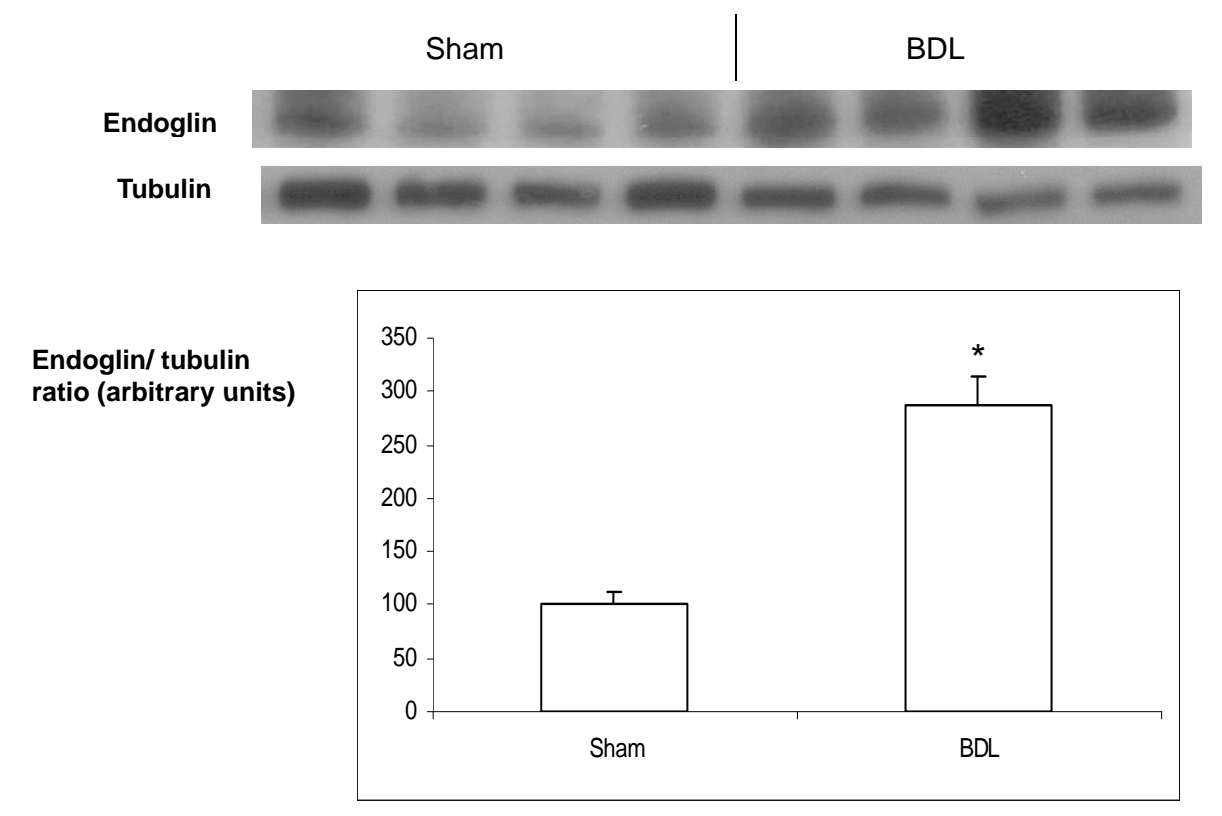

Fig. (2). Representative Western blot analysis of endoglin in livers from Sham operated rats and rats after bile duct ligation. Bar graphs showing the quantification (mean \pm standard error of the mean) of optical densities of 8 samples per group in two different gels, corrected by tubulin expression. $* \mathrm{p}<0.05$ versus sham-operated group. 
A

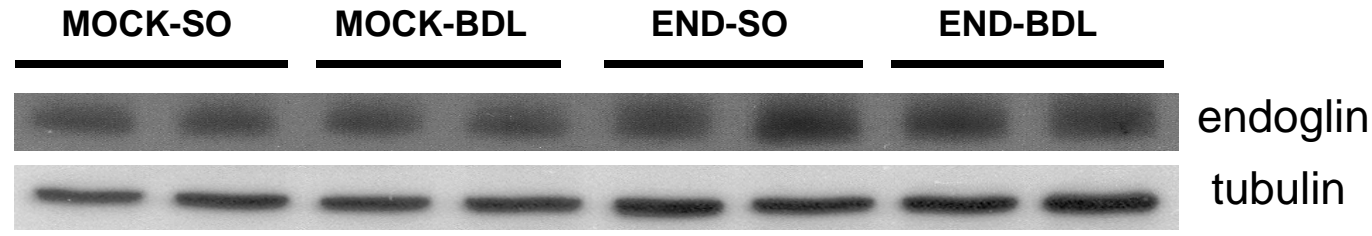

B
Endoglin/
tubulin ratio
(arbitrary units)

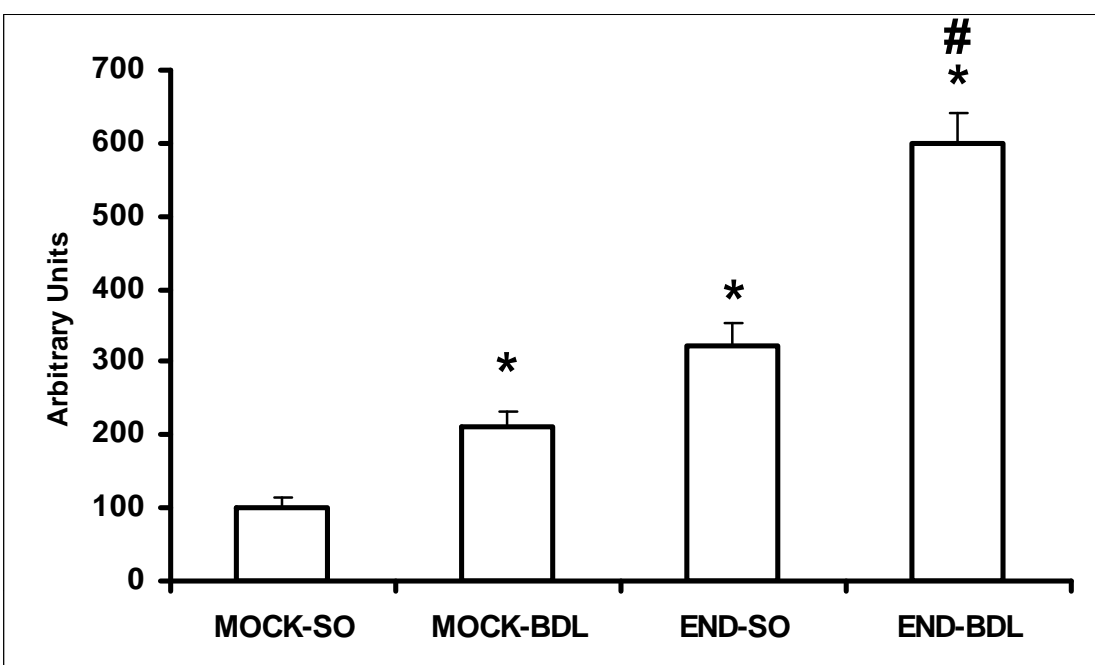

Fig. (3). (A). Representative Western blot analysis of endoglin in livers from the different groups. (B). Bar graphs showing the quantification (mean \pm standard error of the mean) of optical densities of 8 samples per group in two different gels, corrected by tubulin expression. Abbreviations: MOCK-SO: sham operated rats transfected with vehicle solution. END-SO: rats subjected to a sham operation then transfected with endoglin. MOCK-BDL: rats with bile duct ligation transfected with vehicle solution. END-BDL: rats with bile duct ligation transfected with endoglin. * $\mathrm{p}<0.05$ vs MOCK-SO; \# $\mathrm{p}<0.05$ vs END-SO.

\section{Effect of Endoglin Transfection in Liver Fibrosis}

Liver damage was evaluated by measuring plasma concentration of total bilirubin, alkaline phosphatase, aspartate aminotransferase, and alanine aminotransferase (Fig. 4). No significant differences were observed between END-SO and MOCK-SO groups in plasma concentration of total bilirubin, alkaline phosphatase, aspartate aminotransferase and alanine aminotransferase. Bile duct ligation increased serum bilirubin concentration and the levels of enzyme activities but there were not significant differences between MOCK-BDL and END-BDL groups.

In MOCK-SO and END-SO, TGF- $\beta 1$ is expressed in portal extracellular spaces and a tiny expression is detected around sinusoids (Fig. 1E and 1F). In MOCK-BDL group, TGF- $\beta$ staining was observed in the same places and is extended to fibrotic areas around ducts newly formed (Fig. 1G). END-BDL rats showed a TGF- $\beta 1$ staining distribution quite similar to that expressed in mock animals, but in this case it is possible to see TGF- $\beta 1$ around hepatocyte plates, mainly were ductular metaplasia is observed (Fig. 1H).

Liver fibrosis has been assessed by different approaches: conventional histological staining, computer assisted image analysis and hydroxyproline content. Light microscopy analysis of slides stained either with hematoxylin and eosin and Masson's trichrome showed that livers from MOCK-SO had a normal pattern with no evident alterations (Fig. 5A).
No alterations in liver structures were observed in END-SO animals (Fig. 5C). Animals from MOCK-BDL group showed proliferation of portal and periportal biliary ductules. In these areas the ducts newly formed had dilated lumens and irregular epitheliums with peripheral intense fibrosis (Fig. 5B). Similar structural changes were observed in ENDBDL group (Fig. 5D). However in these animals the loss of plate structure and the diffused hepatocyte, ductular metaplasia with fibrosis were more severe.

Fig. (6A) showed the computer assisted image analysis of Sirius red staining. It is observed that rats subjected to BDL had a markedly increased in fibrotic areas as compared with non-ligated animals, but no significant differences were observed when compared END-BDL-S and MOCK-BDL-S groups between them. No differences are seen when compared MOCK-SO and END-SO, however if compare MOCK-SO and parenchymal zones of ligated animals (MOCK-BDL-P and END-BDL-P) differences are detected. END-SO group has no differences with END-BDL-P group, however, a significant difference is observed when compared with MOCK-BDL-P.

To evaluate the amount of collagen present in liver tissue in a quantitative manner, the hydroxyproline content measured in END-BDL rats was 3.6 higher than in END-SO animals. The hydroxyproline content in MOCK-BDL rats was 3.2-fold higher than in MOCK-SO group (Fig. 6B). 

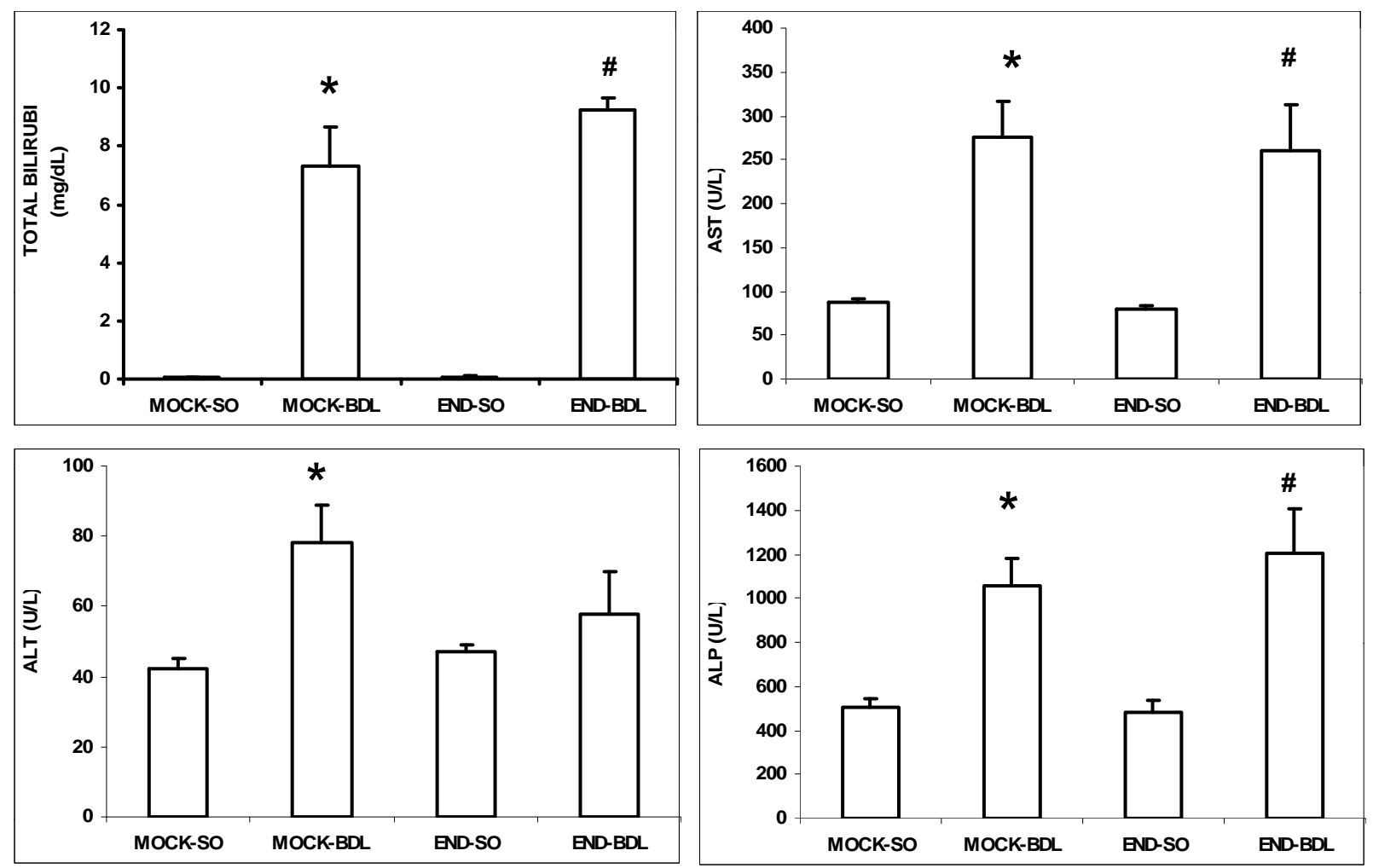

Fig. (4). Plasma levels of total bilirubin and liver enzymes activities. Groups are MOCK-SO: sham operated rats and transfected with vehicle solution $(n=7)$. MOCK-BDL: rats with bile duct ligation and transfected with vehicle solution $(n=12)$. END-SO: rats subjected to a sham operation then transfected with endoglin $(n=7)$. END-BDL: rats with bile duct ligation and transfected with endoglin ( $n=10)$. ALP (alkaline phosphatase), ALT (alanine aminotransferase) and AST (aspartate aminotransferase). Values are means \pm SEM. * $<0.05$ vs MOCK-SO rats, $\# \mathrm{p}<0.05$ vs END-SO rats.

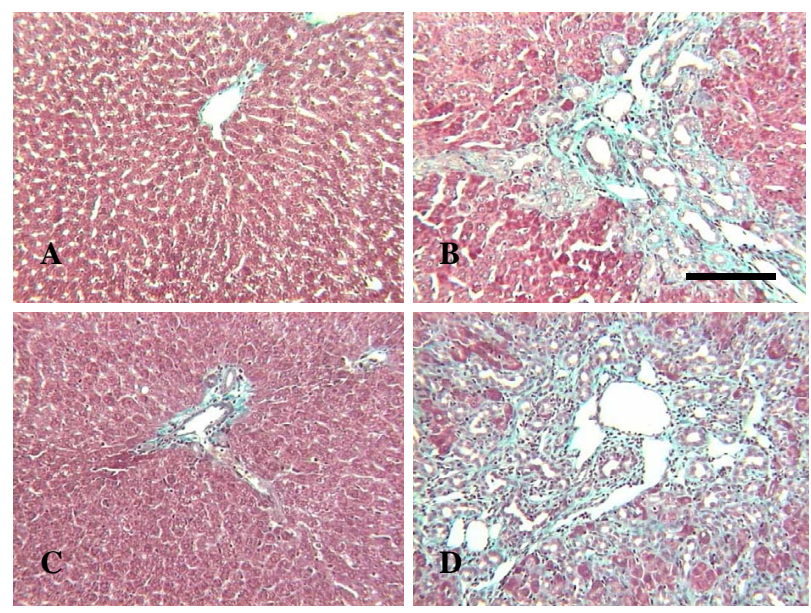

Fig. (5). Light microscopy photomicrographs showing representative images of liver slices stained with Masson's trichrome corresponding to MOCK-SO: sham operated rats and transfected with vehicle solution (A). END-SO: rats subjected to a sham operation and transfected with endoglin (B). MOCK-BDL: rats with bile duct ligation transfected with vehicle solution (C). END-BDL: rats with bile duct ligation transfected with endoglin (D). Bar is $100 \mu \mathrm{m}$.

\section{DISCUSSION}

Experimental bile duct ligation (BDL) serves as an excellent model of hepatic fibrosis. In our study, the amount of collagen in liver parenchyma, quantified by liver hydroxyproline concentrations, was increased eighteen days after obstruction. Serum bilirubin and liver enzymes were also significantly increased. These results are similar to those previously reported for the same model and experimental period [41, 42]. The increase in body weight was in the range previously described by others authors [42-44], and could be related to the marked elevation in liver weight, as indicated by the hepatosomatic ratio. Both collagen accumu- 


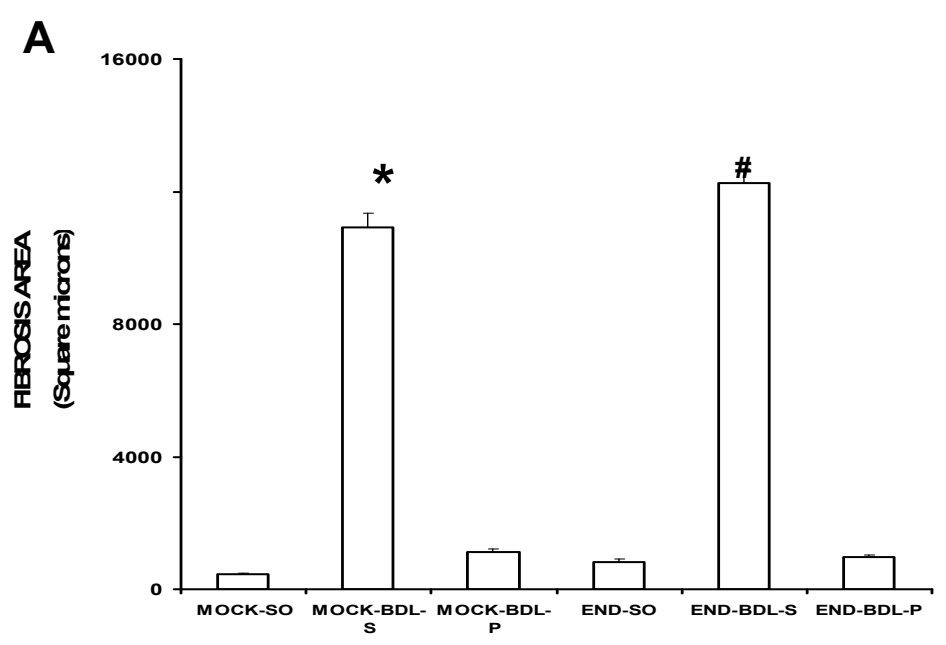

B

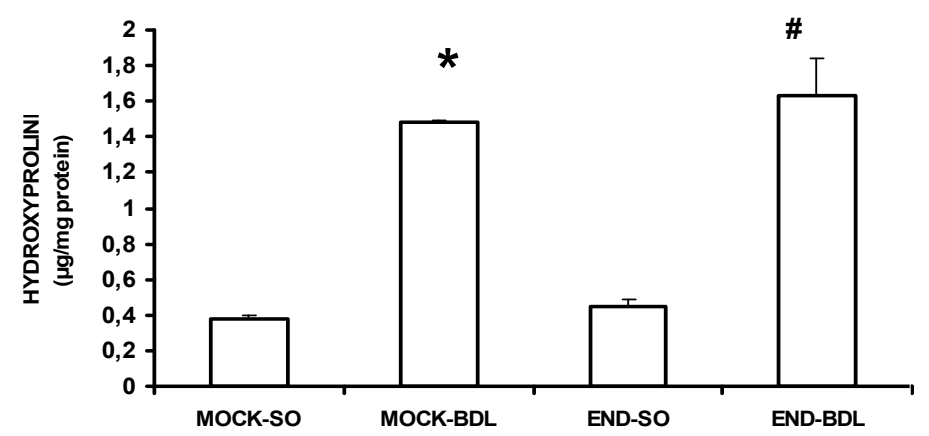

Fig. (6). (A) Morphometrical quantification of liver fibrosis in the septum (S) and parenchyma (P). (B) Hydroxyproline content in the liver of the different experimental groups. Abbreviations: MOCK-SO: sham operated rat transfected with vehicle solution. MOCK-BDL: rats with bile duct ligation and transfected with vehicle solution. END-SO: rats subjected to a sham operation then transfected with endoglin. ENDBDL: rats with bile duct ligation and transfected with endoglin. Data are means \pm SEM. *p<0.05 vs MOCK-SO. \#p<0.05 vs END-SO.

lation and bile duct proliferation would thus contribute to changes in liver weight.

This study also detected a marked increase in hepatic endoglin expression after BDL. These results agree with previous studies reporting endoglin overexpression in animal models of organ fibrosis [27, 28]. After BDL, endoglin is clearly expressed in non-parenchymal cells. In addition, a clear expression was also observed in fibrosed areas around areas of ductular proliferation. These data agree with the observation of Medina et al., [45] who have observed in biopsies from patients with primary biliary cirrhosis that endoglin was expressed in sinusoidal endothelial cells, particularly in periportal areas, in association with the inflammatory infiltrates.

The mechanism responsible for the increase in endoglin expression is not clear but could be related to TGF- $\beta 1$ overexpression. Animal models of experimental liver fibrosis, such as carbon tetrachloride-induced fibrosis [46], bile duct ligation [31] or schistosomiasis infection [11] have reported increased concentrations of TGF- $\beta 1$ very early in the course of fibrogenesis in these animal models. TGF- $\beta 1$-induced endoglin expression has been shown in cultured human monocytes and in the U-937 monocyte line [47], and in cultured mesangial cells [24]. Whereas mesangial cell is major profibrogenic cell in the kidney, hepatic stellate cells is the most profibrogenic cell type in the liver, and endoglin has been reported to be present in hepatic stellate cells, which are a target for TGF- $\beta 1$ [48]. Thus, it could be suggested that increased endoglin expression in livers with BDL may occur as a consequence of the increase in TGF- $\beta 1$. However, in our study, we detect endoglin mainly in endothelial cells that are the cells with the higher endoglin content, and also respond to TGF- $\beta 1$ increasing endoglin expression [49].

About the role of increased endoglin expression in liver fibrosis, previous studies have obtained preliminary evidence that endoglin overexpression can reduce the effects of TGF$\beta 1$ on extracellular matrix synthesis and cell proliferation $[34,47,50]$. Thus, one might expect that the increased expression of endoglin by liver tissue would contribute to a reduction in the amount of TGF- $\beta 1$-induced ECM production. Thus, to test this hypothesis, the next purpose of our study has been to assess the effect of endoglin overexpression in the liver on BDL-induced liver fibrosis. For this purpose we have performed specific liver transfection as previously described by us [35] with a plasmid containing fulllength human endoglin (h-end) cDNA. The effectiveness of endoglin transfection has been assessed by either Western blot or inmunohistochemistry. Western blot using several antibodies against different epitopes of the molecule, demonstrated that endoglin expression was higher in h-end- than in 
mock-transfected rats. Inmunohistochemistry using an antihuman endoglin antibody revealed almost no stain in mocktransfected. In h-end transfected rats, inmunohistochemistry revealed the presence of endoglin in the sinusoidal endothelial cells, thus demonstrating the efficacy of the transfection method.

However, our results demonstrate that an increased endoglin expression do not imply an improvement neither in liver function nor in liver fibrosis after BDL, when compared with mock-transfected rats. In other experimental model of organ fibrosis such as unilateral ureteral obstruction [27] results shown that the absolute level of endoglin is not critical for the renal fibrosis process. This negative result might be explained by the fact that endoglin and TGF- $\beta 1$ protein and receptors are not coexpressed in the same cell type. Roulot et al., [32] show a dissociation of the antiproliferative and profibrogenic effects of TGF- $\beta 1$ that may be determined at the level of the receptor. The TGF- $\beta 1$ type II receptor is down-regulated during liver fibrosis, likely as a direct consequence of increased TGF- $\beta 1$ release. Growth-inhibitory effects of TGF- $\beta 1$ are reduced commensurately, but profibrogenic effects are maintained. This uncoupling of the effects of TGF- $\beta 1$ probably reflects quantitative changes in TGF- $\beta 1$ receptor signaling. The down-regulation of the T $\beta$ RII in smooth muscle cells derived from human atherosclerotic lesions is associated with loss of an antiproliferative response to TGF- $\beta 1$ but an overproduction of ECM components [51].

In conclusion, our results shown that BDL induces endoglin overexpression in rat liver. In addition, the specific liver overexpression of endoglin induced by human endoglin overexpression has not beneficial effects on liver fibrosis induced by BDL in rats.

\section{ACKNOWLEDGEMENTS}

This study was supported by grants from Junta de Castilla y León (SA030/02 to F.P.B.) and Comisión Interministerial de Ciencia y Tecnología (CICYT grant SAFT-950533 to J.M.L.-N.). The authors wish to thank Dr. F. Sanchez-Madrid (Hospital de la Princesa, Madrid, Spain) for the gift of TEA antibody, and Mrs. Angustias Pérez for histology and immunohistochemical technical assistance.

\section{REFERENCES}

[1] Roberts AB, Sporn MB, Assoian RK, et al. Transforming growth factor type beta: rapid induction of fibrosis and angiogenesis in vivo and stimulation of collagen formation in vitro. Proc Natl Acad Sci USA 1986; 83: 4167-71.

[2] Ignotz RA, Massague J. Transforming growth factor-beta stimulates the expression of fibronectin and collagen and their incorporation into the extracellular matrix. J Biol Chem 1986; 261 : 4337-45.

[3] Balza E, Borsi L, Allemanni G, Zardi L. Transforming growth factor beta regulates the levels of different fibronectin isoforms in normal human cultured fibroblasts. FEBS Lett 1988; 228: 42-4.

[4] Edwards DR, Murphy G, Reynolds JJ, et al. Transforming growth factor beta modulates the expression of collagenase and metalloproteinasee inhibitor. EMBO J 1987; 6: 1899-904.

[5] Laiho M, Saksela O, Keski-Oja J. Transforming growth factor-beta induction of type-1 plasminogen activator inhibitor. Pericelullar deposition and sensitivity to exogenous urokinase. J Biol Chem 1987; 262: 17467-74.

[6] Lin HY, Moustakas A, Knaus P. The soluble exoplasmic domain of the type II transforming growth factor (TGF)-beta receptor. A heterogeneously glycosylated protein with high affinity and selectivity for TGF-beta ligands. J Biol Chem 1995; 270: 2747-54.

[7] Wrana JL, Attisano L, Carcamo J, et al. TGF beta signals through a heteromeric protein kinase receptor complex. Cell 1992; 71: 100314.

[8] Inagaki M, Moustakas A, Lin HY, Lodish HF, Carr BI. Growth inhibition by transforming growth factor beta (TGF-beta) type I is restored in TGF-beta-resistant hepatoma cells after expression of TGF-beta receptor type II cDNA. Proc Natl Acad Sci USA 1993; 90: 5359-63.

[9] Bhushan A, Lin HY, Lodish HF, Kintner CR. The transforming growth factor beta type II receptor can replace the activin type II receptor in inducing mesoderm. Mol Cell Biol 1994; 14: 4280-5.

[10] ten Dijke P, Yamashita H, Ichijo H, et al. Characterization of type I receptors for transforming growth factor-beta and activin. Science 1994; 26: 101-4.

[11] Czaja MJ, Weiner FR, Flanders KC, et al. In vitro and in vivo association of transforming growth factor-beta 1 with hepatic fibrosis. J Cell Biol 1989; 108: 2477-82.

[12] Matsuoka M, Tsukamoto H. Stimulation of hepatic lipocyte collagen production by Kupffer cell-derived transforming growth factor beta: implication for a pathogenetic role in alcoholic liver fibrogenesis. Hepatology 1990; 11: 599-605.

[13] Rieder H, Armbrust T, Meyer zum Buschenfelde KH, Ramadori G. Contribution of sinusoidal endothelial liver cells to liver fibrosis: expression of transforming growth factor-beta 1 receptors and modulation of plasmin-generating enzymes by transforming growth factor-beta 1. Hepatology 1993; 18: 937-44.

[14] Knittel T, Janneck T, Muller L, Fellmer P, Ramadori G. Transforming growth factor beta 1-regulated gene expression of Ito cells. Hepatology 1996; 24: 352-60.

[15] Castilla A, Prieto J, Fausto N. Transforming growth factors beta 1 and alpha in chronic liver disease. Effects of interferon alfa therapy. New Engl J Med 1991; 324: 933-40.

[16] Casini A, Pinzani M, Milani S, et al. Regulation of extracellular matrix synthesis by transforming growth factor beta 1 in human fatstoring cells. Gastroenterology 1993; 105: 245-53.

[17] Bedossa P, Peltier E, Terris B, Franco D, Poynard T. Transforming growth factor-beta 1 (TGF-beta 1 ) and TGF-beta 1 receptors in normal, cirrhotic and neoplastic human livers. Hepatology 1995; 21: 760-6.

[18] Clouthier DE, Comerford SA, Hammer RE. Hepatic fibrosis, glomerulosclerosis and a lipodystrophy-like syndrome in PEPCKTGF-beta 1 transgenic mice. J Clin Invest 1997; 100: 2697-713.

[19] Sanderson N, Factor V, Nagy P, et al. Hepatic expression of mature transforming growth factor beta 1 in transgenic mice results in multiple tissue lesions. Proc Natl Acad Sci USA 1995; 92: 2572 6.

[20] Gougos A, Letarte M. Identification of a human endothelial cell antigen with monoclonal antibody $44 \mathrm{G} 4$ produced against a pre-B leukemic cell line. J Immunol 1988; 141: 1925-33.

[21] St Jacques S, Cymerman U, Pece N, Letarte M. Molecular characterization and in situ localization of murine endoglin reveal that it is a transforming growth factor $-\beta$ binding protein of endothelial and stromal cell. Endocrinology 1999; 134: 2645-57.

[22] Lastres P, Bellón. T, Cabañas C, et al. Regulated expression on human macrophages of endoglin, an Arg-Gly-Asp-containing surface antigen. Eur J Immunol 1992; 22: 393-7.

[23] Adam PJ, Clesham GJ, Weissberg PL. Expression of endoglin mRNA and protein in human vascular smooth muscle cells. Biochem Biophys Res Commun 1998; 247: 33-7.

[24] Rodríguez-Barbero A, Obreo J, Eleno N, et al. Endoglin expression in human and rat mesangial cells and its up-regulation by TGF- $\beta 1$. Biochem Biophys Res Commun 2001; 282: 142-7.

[25] Cheifetz S, Bellón T, Calés C, et al. Endoglin is a component of the transforming growth factor- $\beta$ receptor system in human endothelial cells. J Biol Chem 1992; 267: 19027-30.

[26] Barbara NP, Wrana JL, Letarte M. Endoglin is an accessory protein that interacts with the signaling receptor complex of multiple members of the transforming growth factor- $\beta$ superfamily. J Biol Chem 1999; 274: 584-94.

[27] Rodríguez-Peña A, Prieto M, Duwel A, et al. Up-regulation of endoglin, a TGF-beta-binding protein, in rats with experimental renal fibrosis induced by renal mass reduction. Nephrol Dial Transplant 2001; 16: 34-9. 
[28] Rodríguez-Peña A, Eleno N, Duwel A, et al. Endoglin, upregulation during experimental renal interstitial fibrosis in mice. Hypertension 2002; 40: 713-20.

[29] Roy-Chaudhury P, Simpson JG, Power DA. Endoglin, a transforming growth factor-beta-binding protein, is upregulated in chronic progressive renal disease. Exp Nephrol 1997; 5: 55-60.

[30] Quackenbush EJ, Gougos A, Baumal R, Letarte M. Differential localization within human kidney of five membrane proteins expressed on acute lymphoblastic leukemia cells. J Immunol 1986; 136: 118-24.

[31] Milani S, Herbst H, Schuppan D, Stein H, Surrenti C. Transforming growth factors beta 1 and beta 2 are differentially expressed in fibrotic liver disease. Am J Pathol 1991; 139: 1221-9.

[32] Roulot D, Sevcsik A-M, Coste T, Strosberg AD, Marullo S. Role of transforming growth factor $\beta$ type II receptor in hepatic fibrosis: studies of human chronic hepatitis $\mathrm{C}$ and experimental fibrosis in rats. Hepatology 1999; 29: 1730-8.

[33] Cowan PJ, Tsang D, Pedic CM, et al. The human ICAM-2 promoter is endothelial cell-specific in vitro and in vivo and contains critical Sp1 and GATA binding sites. J Biol Chem 1998; 273: 11737-44.

[34] Letamendia A, Lastres P, Botella LM, et al. Role of endoglin in cellular responses to transforming growth factor-beta. A comparative study with betaglycan. J Biol Chem 1998; 273: 33011-9.

[35] Velasco B, Ramirez JR, Relloso M, Li C, Kumar S, López-Bote JP. Vascular gene transfer driven by endoglin and ICAM-2 endothelial-specific promoters. Gene Ther 2001; 8: 897-904.

[36] López Novoa JM. Intrasplenic infusion. A simple way for intraportal infusion in the rat. Experientia 1981; 37: 536-7.

[37] Criado M, Flores O, Ortiz MC, et al. Elevated glomerular and blood mononuclear lymphocyte nitric oxide production in rats with chronic bile duct ligation: role of inducible nitric oxide synthase activation. Hepatology 1997; 26: 268-76,

[38] Mayoral P, Criado M, Hidalgo F, et al. Effects of chronic nitric oxide activation or inhibition on early hepatic fibrosis in rats with bile duct ligation. Clin Sci (Lond) 1999; 96: 297-305.

[39] Pichuantes S, Vera S, Bourdeau A, et al. Mapping epitopes to distinct regions of the extracellular domain of endoglin using bacterially expressed recombinant fragments. Tissue Antigens 1997; 50: 265-76.
[40] Luque A, Cabanas C, Raab U, et al. The use of recombinant vaccinia virus to generate monoclonal antibodies against the cellsurface glycoprotein endoglin. FEBS Lett 1997; 413: 265-8.

[41] Rioux KP, Sharkey KA, Wallace JL, Swain MG. Hepatic mucosal mast cell hyperplasia in rats with secondary biliary cirrhosis. Hepatology 1996; 23: 888-95.

[42] Krahenbuhl S, Talos C, Lauterburg BH, Reichen J. Reduced antioxidative capacity in liver mitochondria from bile duct ligated rats. Hepatology 1995; 22: 607-12.

[43] Aronson DC, de Haan J, James J, et al. Quantitative aspects of the parenchyma-stroma relationship in experimentally induced cholestasis. Liver 1988; 8: 116-26.

[44] Ohara N, Schaffner T, Reichen J. Structure-function relationship in secondary biliary cirrhosis in the rat. Stereologic and hemodynamic characterization of a model. J Hepatol 1993; 17: 155-62.

[45] Medina J, Sanz-Cameno P, García-Buey L, Martín-Vílchez S, López-Cabrera M, Moreno-Otero R. Evidence of angiogenesis in primary biliary cirrhosis: an immunohistochemical descriptive study. J Hepatol 2005; 42: 124-31.

[46] Brenner DA, Veloz L, Jaenisch R, Alcorn JM. Stimulation of the collagen alpha 1 (I) endogenous gene and transgene in carbon tetrachloride-induced hepatic fibrosis. Hepatology 1993; 17: $287-$ 92.

[47] Lastres P, Letamendía A, Zhang H, et al. Endoglin modulates cellular responses to TGF-beta 1. J Cell Biol 1996; 133: 1109-21.

[48] Meurer SK, Tihaa L, Lahme B, Gressner AM, Weiskirchen R. Identification of endoglin in rat hepatic stellate cells: new insights into transforming growth factor beta receptor signaling. J Biol Chem 2005; 280: 3078-87.

[49] Bernabeu C, Lopez-Novoa JM, Quintanilla M. The emerging role of TGF-beta superfamily coreceptors in cancer. Biochim Biophys Acta 2009; 1792: 954-73.

[50] Díez-Marques L, Ortega-Velazquez R, Langa C, et al. Expression of endoglin in human mesangial cells: modulation of extracellular matriz síntesis. Biochem Biophys Acta 2002; 158: 36-44.

[51] McCaffrey TA, Pomerantz KB, Sanborn TA, et al. Specific inhibition of eIF-5A and collagen hydroxylation by a single agent. Antiproliferative and fibrosuppressive effects on smooth muscle cells from human coronary arteries. J Clin Invest 1995; 95: 446-55.

CC Pérez-Barriocanal et al.; Licensee Bentham Open.

This is an open access article licensed under the terms of the Creative Commons Attribution Non-Commercial License (http://creativecommons.org/licenses/ by-nc/3.0/) which permits unrestricted, non-commercial use, distribution and reproduction in any medium, provided the work is properly cited. 